\title{
A conceptual model to minimise operational cost for free shuttle buses: a case study in Macau
}

\section{Sen Qiao}

School of Business,

Macau University of Science and Technology,

Macau, 999078, China

Email: qiaosenboy@163.com

\section{Xiangnan Tao*}

Business School,

Nanjing University,

Nanjing, Jiangsu, 210000, China

Email: Xntao@nju.edu.cn

${ }^{*}$ Corresponding author

\section{Rufei Ma}

School of Business,

Macau University of Science and Technology,

Macau, 999078, China

Email:rfma@must.edu.mo

\section{Xin-long Xu}

College of Business,

Hunan Agricultural University,

Changsha, 410128, China

Email:xu78744359@gmail.com

\section{Hsing Hung Chen}

School of Business,

Macau University of Science and Technology,

Macau, 999078, China

Email: hhchen2910@yahoo.com

\begin{abstract}
To facilitate more convenient travel as the economy of Macau expands, the government of Macau has allowed casinos to add free shuttle buses (FSB) and drivers. In this paper, we optimise the operation cost of FSB based on the number of FSB and FSB's driver population in Macau. Firstly, we investigate the operational conditions of the FSB in each depot, including the transit time of FSB and the number of passengers. Then, we propose a
\end{abstract}


series of integer programming models to optimise the population of FSB and FSB drivers. Finally, through a practical demonstration using Excel to solve the linear programming (LP) model, this paper concludes that the numbers of FSB and drivers have a reduction of $43.68 \%$ and $33.6 \%$, respectively. It implies that the operation cost of FSB could be reduced by $270,900,000 \mathrm{HKD}$ in purchasing of FSB and 38,678,400 $\mathrm{HKD} /$ year in employing drivers of FSB.

Keywords: cost reduction; bus scheduling; optimisation; free shuttle buses; FSB.

Reference to this paper should be made as follows: Qiao, S., Tao, X., Ma, R., Xu, X-L. and Chen, H.H. (2016) 'A conceptual model to minimise operational cost for free shuttle buses: a case study in Macau', Int. J. Heavy Vehicle Systems, Vol. 23, No. 1, pp.40-59.

Biographical notes: Sen Qiao received his $\mathrm{PhD}$ in Management from the School of Business, Macau University of Science and Technology. His research area includes accounting and finance.

Xiangnan Tao is a Professor, PhD Supervisor at the Business School, Nanjing University. His research area includes organisational behaviour and marketing management.

Rufei Ma is an Associate Professor at the School of Business, Macau University of Science and Technology. His research area includes corporate finance, exchange rate and international financial market.

Xin-long $\mathrm{Xu}$ is a Lecturer at the College of Business, Hunan Agricultural University. His research area includes banking and finance.

Hsing Hung Chen is a Professor at the School of Business, Macau University of Science and Technology. His research area includes financial management, operations management and performance evaluation, new energy management.

\section{Introduction}

In recent decades, China has been regarded as a rising dragon because of the greatest development potential of economics. Under this kind of environment, public transport is therefore becoming an extremely important method in societies and the bus is the most popular of all land-based public passenger modes. It is however seen as a somewhat monotonous means of supporting mobility and accessibility in contrast to rail and flight, and it offers so much to the travelling public as well as absorbing sustainability opportunities. This paper argues that attracting and retaining public transport patronage, and bus in particular, is a growing challenge in many countries and will be further aggravated in economies that are moving towards a high level of economic efficiency, where the desire and ability to own and use the automobile will continue to impact on the future of all forms of land-based public transport, especially for the majority of urban and regional travel. 
This paper chooses Macau as an example, which is located in the southern part of China. Its economy develops dramatically, and during the first three quarters of 2012, the registered year-on-year GDP increases of $31.4 \%$ (AMCM, 2012). Tourism is the backbone of Macau's economy and much of it geared towards gambling. Owing to the opening policy of hotels and casinos, and China's easing of travel restrictions, a rapid rise in the number of visitors happens from 9.1 million visitors in 2000, 18.7 million visitors in 2005 and 28.2 million visitors in 2011 , with over $50 \%$ of the arrivals coming from mainland China and another 30\% from Hong Kong (DSEC, 2012). In fact, Macau is expected to accept around 30-32 million visitors in 2014 (Macau Hub, 2013). Thus, The World Tourism Organization currently rates Macau as one of the world's top tourism destinations.

With the rapid development of Macau economy, the number of vehicles in Macau also increases dramatically. Particularly, the free shuttle buses (FSB) has come into service to provide convenient and quick travel for those who visit the casinos when the Sands and Wynn casinos opened in 2003. Because of the quick development of the casinos, the population of FSB grows remarkably. Nevertheless, a large number of deadhead trips and disorderly expansion has seriously affected the traffic operation. On the basis of the field survey, we find that some casinos separated by a wall setup their own sites for FSB to avoid potential loss of customers, which makes the existing overburdened road traffic worse. Therefore, it is urgent and challenging to build up a feasible model to supervise the operation of FSB to reduce its negative impacts. One of the most effective methods may be the optimisation of the number of FSB. Furthermore, the vast majority of FSB with high no-load ratio may lead to high waste in personnel cost for drivers and operational cost of FSB. Then, optimising the driver number of FSB seems essential to reduce the operation cost of casinos.

For the purpose of reducing the operation cost of FSB based on the optimisation of the number of FSB and FSB's driver population in Macau, this paper proposes a series of integer linear programming (LP) models to optimise the population of FSB and FSB's driver. The rest of this paper is organised as follows. In Section 2, we review the existing literatures for the above two targets. Then, we construct a mathematical model in Section 3 and analyse a case study in Section 4. Finally, conclusions and suggestions are provided in Section 5.

\section{Literature review}

In the early study, FSB scheduling belongs to the family of vehicle scheduling problems (VSP), which was proposed by Dantzig and Ramser (1959). They studied the driving routes to make vehicles meet certain constraints (such as demand, departures, vehicle capacity restrictions, travel restrictions, time limits, etc.) to pass through a series of supply points or demands points orderly, and achieve the purpose such as the shortest distance, minimum cost and time consuming as little as possible. Later research of VSP mainly focuses on algorithms, such as heuristic algorithms, branch-and-price algorithms, branch and bound: column generation and variable elimination, Eligen-algorithms, etc. For instance, Savelsberg and Sol (1998) presented a column generation approach for a dynamic and generalised pickup and delivery problem. They showed dynamic routing of independent vehicles (DRIVE), a planning module to be incorporated in a decision support system for the direct transportation at Van Gend and Loos BV. Besides, 
Gronalt et al. (2003) applied the heuristic algorithm to set delivery integration problem. They deal with the pickup and delivery of full truckloads under time window constraints. Moreover, Yang et al. (2007) presented an optimisation model for a bus network design based on the coarse-grain parallel ant colony algorithm (CPACA). While Chotiros et al. (2008) developed the Eligen-algorithm for solving the multiple-depot vehicle scheduling problems (MDVSPs). They consider the modelling of city bus scheduling problems to optimise the number of buses and their scheduling in Bangkok. After then, Qi (2009) developed a new scheduling model to solve schedule vehicle for package transportation between the hub and the transfer stations. While Hadjar and Soumis (2009) applied a dynamic time windows reduction technique to solve the multiple-depot vehiclescheduling problems with time windows (MDVSPTW), Stefan et al. (2010) used path-reduced costs to eliminate arcs in routing and scheduling problem.

For the driver optimisation, Cooper (1989) introduced the activity-based costing $(\mathrm{ABC})$ problem, and claimed that $\mathrm{ABC}$ systems achieved their improved accuracy over traditional volume-based cost systems by using multiple cost drivers (instead of just one or two) to trace the cost of production activities. Then, Bahad and Balachandran (1993) provided an optimisation model that balanced savings in information processing costs with loss of accuracy and showed how to determine the number of drivers and identified the representative cost of drivers. Levitan and Gupta (1996) used genetic algorithms to optimise the selection of drivers in $\mathrm{ABC}$ and addressed a cost-drivers optimisation (CDO) problem in which two separate but interrelated decisions were considered. Additionally, Kim and Han (2003) applied a hybrid genetic algorithm and neural network approach in $\mathrm{ABC}$. They proposed hybrid artificial intelligence techniques to resolve these problems. Recently, Steinzen et al. (2010) solved the integrated vehicle and crew-scheduling problem in public transit with multiple depots by a time-space network approach.

However, because of the special traffic characteristics in Macau, the driving routes of FSB are fixed basically. It seems that solving the scheduling problem of FSB using the aforementioned methods could not be effective. To the best of our knowledge, there was only one paper focusing on the optimal operation of FSB in Macau, which optimised the schedules of FSB in Macau (Shi et al., 2010). Considering that Macau has been one of the regions with the highest density of the vehicle population, it is urgent to optimise the vehicle and driver populations. To reduce operation cost while retaining the same service level in casinos, the paper proposes a series of integer programming models to optimise the population of FSB and the number of FSB's drivers. We believe that the proposed models are creative and unique with significant difference from the previous models.

\section{Methodologies}

\subsection{Optimising the population of FSB}

This paper sets some assumptions to build an effective model in order to reduce the population of the FSB in Macau:

- the passenger demand for one route is independent of that for the other routes

- the passenger demand is independent of the frequency of FSB departures 
- the FSB speed is constant between each depot and the corresponding casino

- the types of FSBs are uniform and the capacity is fixed

- the tolerance upper limit of the waiting time for passengers is set as $16.3 \mathrm{~min}$.

Let $Y$ be the total number of FSB, $D_{2 k+1,2 k+3}$ be the number of FSBs from each casino to each depot during the time period $[2 k+1,2 k+3], A_{2 k+1,2 k+3}$ be the number of FSBs from each depot to each casino during the time period [ $2 k+1,2 k+3], M_{2 k+1,2 k+3}$ be the number of passengers visiting one casino during the time period $[2 k+1,2 k+3], N_{2 k+1,2 k+3}$ be the number of passengers leaving for one depot during the time period $[2 k+1,2 k+3]$, $C$ be the number of seats provide by the FSB, $T_{1}$ be the transit time of FSBs from the corresponding casino to some depot (including waiting time), and $T_{2}$ be the transit time of FSBs from one depot to the corresponding casino (include waiting time), where $k=4, \ldots, 9,[2 k+1,2 k+3]$ be the working time is from 9:00 AM and time period is $2 \mathrm{~h}$. For instance, when $k=9,2 k+1=19$ and $2 k+3=21$. The LP model is built as follows:

$$
\begin{aligned}
& \operatorname{Min} Y=D_{2 k+1,2 k+3}+A_{2 k+1,2 k+3} \\
& D_{2 k+1,2 k+3} \leq \operatorname{Max}\left\{2 \times 60 / 16.3, M_{2 k+1,2 k+3} / C\right\} \\
& A_{2 k+1,2 k+3} \leq \operatorname{Max}\left\{2 \times 60 / 16.3, N_{2 k+1,2 k+3} / C\right\} \\
& D_{2 k+1,2 k+3} \geq\left[T_{1}+T_{2}\right] / 16.3 \\
& A_{2 k+1,2 k+3} \geq\left[T_{1}+T_{2}\right] / 16.3
\end{aligned}
$$

where $D_{2 k+1,2 k+3}, A_{2 k+1,2 k+3}, M_{2 k+1,2 k+3}, N_{2 k+1,2 k+3} \in Z^{+}, k=4, \ldots, 9$.

Inequality (1) shows that the number of FSBs from each casino to each depot is at most the minimum number of departures from the casino to the depot during the same 2-h period. Inequality (2) is similar to inequality (1) with the opposite operational direction. Inequality (3) suggests that the population of FSBs from each casino to each depot is at least the departures of vehicles at intervals of $16.3 \mathrm{~min}$. Inequality (4) is similar to inequality (3) with the opposite operational direction.

\subsection{Optimising the population of FSB's drivers}

To build an effective model to reduce the population of the FSB's drivers in Macau, this study sets some assumptions as follows:

- Full time drivers: They work from 9 AM to 9 PM, take a 1-h lunch break (half of them start at 11, the other half start at noon). Currently only 608 are available.

- $\quad$ Part time drivers: They work for six consecutive hours (no lunch break). They can begin to work at 9, 10,11, 12, 13, 14 or 15 PM. Their driving hours cannot exceed $50 \%$ of the day's minimum requirement. It should be $(336+287+388+451+552+220) / 2=1117$.

- From the previous result of optimising the population of FSB, the minimal number of drivers in each period is shown in Table 1. 
Let $Z$ be the total number of FSB's drivers, $F$ be the number of full-time drivers (all work during the period 9-21), $P_{1}$ be the number of part-time drivers who work during the period $9-15, P_{2}$ be the number of part-time drivers who work during the period 10-16, $P_{3}$ be the number of part-time drivers who work during $11-17, P_{4}$ be the number of part-time drivers during 12-18, $P_{5}$ be the number of part-time drivers during 13-19, $P_{6}$ be the number of part-time drivers during 14-20, and $P_{7}$ be the number of part-time drivers during 15-21.

Table 1 The minimal number drivers of each period

\begin{tabular}{lcccccc}
\hline Time & $9-11$ & $11-13$ & $13-15$ & $15-17$ & $17-19$ & $19-21$ \\
\hline Number & 336 & 287 & 388 & 451 & 552 & 220 \\
\hline
\end{tabular}

The model is built as follows:

$$
\begin{aligned}
& \operatorname{Min} Z=F+\left.\right|_{i=1} ^{7} P_{i} \\
& 6\left(P_{1}+P_{2}+P_{3}+P_{4}+P_{5}+P_{6}+P_{7}\right) \leq 1117 \\
& F+P_{1}+P_{2} \geq 336 \\
& 0.5 F+P_{1}+P_{2}+P_{3}+P_{4} \geq 287 \\
& 0.5 F+P_{1}+P_{2}+P_{3}+P_{4}+P_{5}+P_{6} \geq 388 \\
& F+P_{1}+P_{2}+P_{3}+P_{4}+P_{5}+P_{6}+P_{7} \geq 451 \\
& F+P_{4}+P_{5}+P_{6}+P_{7} \geq 552 \\
& F+P_{6}+P_{7} \geq 220 \\
& F \leq 608
\end{aligned}
$$

where $F, P_{1}, P_{2}, P_{3}, P_{4}, P_{5}, P_{6}, P_{7} \in Z^{+}$.

Inequality (5) shows that part-time driver's hours cannot exceed $50 \%$ of the day's minimum requirement. Inequality (6) suggests that the minimal number of drivers during 9-11. Inequality (7) suggests that the minimal number of drivers during 11-13. Inequality (8) suggests that the minimal number of drivers during 13-15. Inequality (9) suggests that the minimal number of drivers during 15-17. Inequality (10) suggests that the minimal number of drivers during 17-19. Inequality (11) suggests that the minimal number of drivers during 19-21. Inequality (12) suggests that the available number of the full-time drivers is at most 608 .

\section{Case study}

\subsection{The current status of FSB}

According to the report of Macau Bureau of Statistics in February 2013, the total number of motor vehicles in Macau was 190,713, growing by $3.2 \%$ with respect to February 
2012. Among these vehicles, there were 80,843 light vehicles, 6313 heavy-duty cars and 102,566 motorcycles, respectively, which grew by $2.2,0.01$ and $4.2 \%$, compared with February 2012. Among heavy-duty cars, there were 1402 tour buses, which was 48 more compared to the same period of the last year and the growth was $3.54 \%$, while the growth of heavy-duty cars was only $0.01 \%$ in that period. From Macau Bureau of Statistics, the majority parts of tour buses mainly come from FSB at each casino.

Figure 1 The map of Macau hotels (see online version for colours)

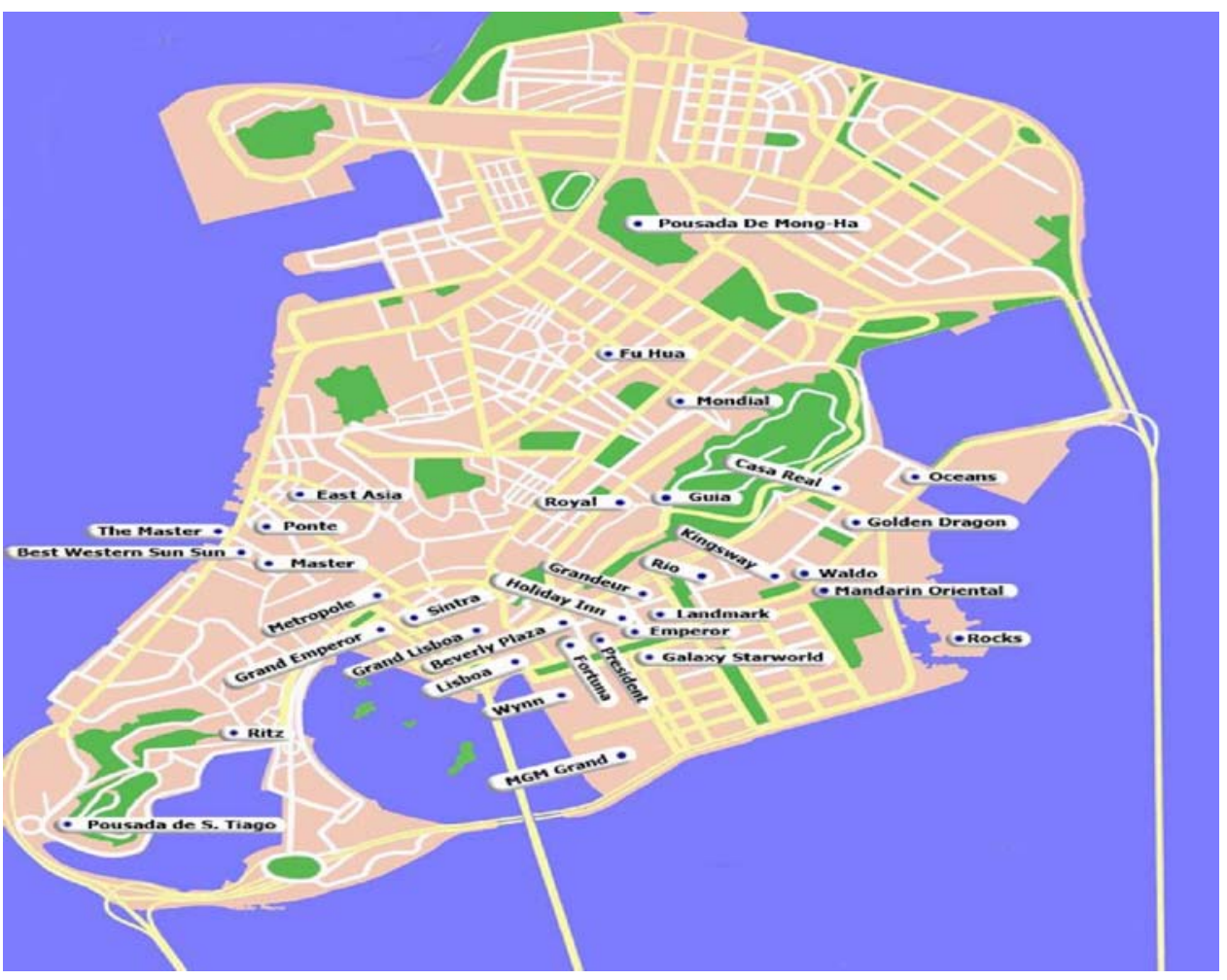

Source: http://www.china-mike.com/china-travel-tips/tourist-maps/ macau-map/

\subsection{Casinos and depots selection}

FSBs take visitors back and forth between casinos and boundary ports (such as Ferry Terminal, Border Gate, Pac On Pier and International Airport of Macau) to scramble the potential customers. At present, there are 35 licenced casinos in Macau, located at many regions of Macau. This paper selects a total of 17 representative casinos as the observation targets to collect data: City of Dreams (COD), Venetian, Plaza, Sands Cotai Central, Galaxy, Grand Emperor, LisboalGrand Lisboa, Wynn, L'Arc, Star World, MGM, Sands, Babylon, Golden Dragon, Casa Real and Oceanus, respectively. Their locations are shown in Figures 1 and 2. 
Figure 2 The map of Taipa and Coloane hotels (see online version for colours)

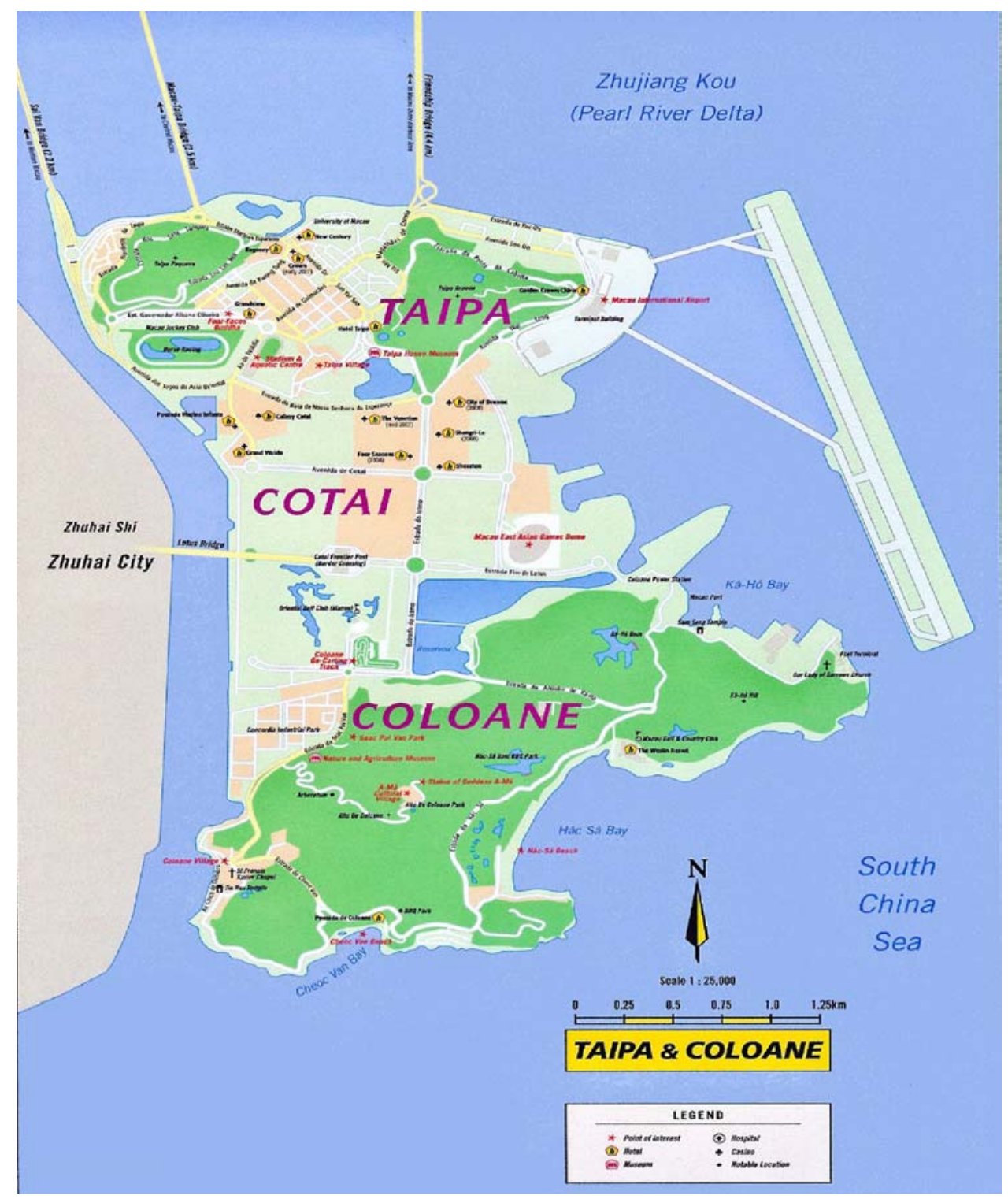

Source: http://mappery.com/Taipa-and-Coloane-Tourist-Map

In general, the FSB runs back and forth from its own casino to Ferry Terminal, Border Gate, Pac On Pier and International Airport of Macau. Some casinos arrange FSBs among them to share their customer resources. For instance, the FSB departs from Venetian to Sands. Some FSBs go back and forth between COD and MGM. Moreover, some casinos also arrange additional FSBs to take passengers to other regions in Macau, such as AVENIDA DE ALMEIDA RIBEIRO, city subdivision of Taipa, and so on. In the above-driving routes, the majority of visitors come from the following depots: Border Gate (Left), Border Gate (Right), Ferry Terminal and Pac On Pier. Moreover, 
about $95 \%$ of the FSBs serve these four depots. Therefore, this paper selects them as the destinations for data collection.

The Border Gate with Portuguese named Portas do Cerco is the gate-connecting border between Macau and Mainland China. There are two major parking lots in Border Gate: Border Gate (Left) and Border Gate (Right). The right parking lot has a long history, and it is the first special parking lot for free bus in Macau, at which a majority of FSBs operate for more than $16 \mathrm{~h}$ each day. With the rapid development of casinos in Macau, the right parking lot could not meet the demands any longer. Hence, parking lot on the left of Border Gate began to put into operation. Owing to less parking space and special position, only the FSBs with two plates are allowed to enter. So far the FSBs in the left parking lot come from the following 13 casinos: Venetian, COD, Sands Cotai Central, Sands, Galaxy, Wynn, Lisboa, Grand Lisboa, MGM, Star World, Grand Emperor, L'Arc and Babylon.

The Ferry Terminal locates at Porto Exterior, Macau Peninsula. It was formerly located near present-day Yaohan Store. As the major transportation junction for waterway passenger transport in Macau, Ferry Terminal mainly undertakes passenger sources from Hong Kong and Shenzhen. Many visitors come from Hong Kong and there is only $60 \mathrm{~km}$ distance between Hong Kong and Macau. With the internationalisation of Macau increases gradually, the number of tourists entering the Ferry Terminal increases quickly. The situation enlarges the pressure of passenger flow volume in Macau Ferry Terminal. Because of area limit, the parking lots on Ferry Terminal cannot drop off/pick up passengers instantly, so there is only one parking location for each casino.

The Pac On Pier is located at Taipa. It provides two berths for hydrofoil and one for ferries, serving as a port of entry into Macau. Visitors mainly are consisting of Hong Kong residents and Mainland China visitors and Diplomats. There is also a visaon-arrival application office for those who require a visa to enter Macau but have not applied prior to arriving at the Pac On Pier. In addition, there is a bus stop outside the pier, as well as a taxi stop. The Pac On Pier provides service to fewer casinos and the parking spaces are sufficient relatively. Until now, the passenger flow volume of Pac On Pier is relatively small, mostly concentrated in the period of holidays.

\subsection{Data collection and calculation}

\subsubsection{FSB schedules and visitors counting}

The service time of the FSBs ranges from $9 \mathrm{AM}$ to $9 \mathrm{PM}$, but there are still some largescale casinos that provide FSB after 9 PM. For example, the last FSB leaving for Border Gate from COD and Venetian is 11:30 PM. However, there are very few casinos providing FSB for Macau Ferry Terminal in other periods. The observation time adopted in this paper is the time interval from 9:00 AM to 9:00 PM and lasts for two months. This time interval meets the operational characteristics of most FSBs well, including peak-hour and low-hour periods. To guarantee the accuracy of data as much as possible, this paper divides the observation data into workday and holiday, respectively. Because the major holidays in Macau only accounts for $6 \%$ of the total year, we do not distinguish weekend from the major holidays and unify them as holidays. The other observation data consists of workdays. At each observation point, there are entrance 
and exit for FSB, which record the arrival schedule, departure schedule, motorcycle type and the number of passengers, respectively. Table 2 is the statistical result of schedules for FSBs at each depot. On the whole, no matter in workdays or holidays, the arrival and departure schedules are essentially stable. The departure and arrival schedules at arrival depots are essentially flat with holiday, but the schedules on holidays have a slight increase.

From the point of the scale of schedules of FSB, Venetian has the most frequent shuttles. In workdays, the arrivals for the four depots by Venetian up to 541 in total, while during holidays, the arrivals increases to 559 (take the arrival schedule of one station, for example). That is, during every $1.33 \mathrm{~min}$ in workdays, $1.28 \mathrm{~min}$ in holidays, there is a bus departing from Venetian to each depot. Following Venetian are Sands with 462 shuttles and Wynn with 432 shuttles.

According to the data of arrival depots, there are total 859 arrivals a day in workdays and 911 arrivals on holidays at Border Gate (L). That is, every 0.84 min during workdays, or 0.79 min during holidays for an arrival. At Border Gate (R), there are 1579 arrivals in workdays and 1658 arrivals on holidays. That is, every $0.45 \mathrm{~min}$ during workdays or 0.43 min on holidays for an arrival. At Pac On Pier, there are 722 arrivals in workdays and 735 arrivals on holidays. That is, every $0.99 \mathrm{~min}$ during workdays or 0.97 min on holidays for an arrival. Therefore, it is concluded that the parking lot on Border Gate (R) is the busiest depot for every casino to depart FSB, while Pac On Pier is the least. And the departures of casino located in Macau Island mainly focus on Ferry Terminal and Border Gate, while for casinos in Cotai Strip, the shuttles departed to Pac On Pier are relatively large.

According to the data of departure depot, at the left of Border Gate, there are total 907 departures on holidays. This means that there is one departure during every 0.79 min on average. At the right of Border Gate, there are total 1568 departures on holidays. It means that there is one departure during every $0.46 \mathrm{~min}$ on average. Ferry Terminal departs 1257 departures on holidays. That is, there is a departure during every $0.57 \mathrm{~min}$ on average. Pac On Pier departs 706 departures on holidays totally. That is, there is one departure during every $1.02 \mathrm{~min}$ on average. Therefore, Border Gate (R) and Ferry Terminal are the depots with most frequent shuttles.

On the basis of the comparison of departures between workdays and holidays, during the workdays, there are 866 arrivals at Border Gate (L), 1509 shuttles at Border Gate (R), 1246 departures at Ferry Terminal, 687 departures at Pac On Pier. During holidays, there are total 907 arrivals at Border Gate (L), 1568 shuttles at Border Gate (R), 1257 schedules at Ferry Terminal and 706 departures at Pac On Pier.

\subsubsection{Capacity and population of FSB}

According to the data from visitors at each casino, Venetian has the largest number of visitors. During workdays, the total number of visitors left Venetian for the four depots up to 11,501 . That is, there are 958 visitors leaving Venetian for each depot during every $1 \mathrm{~h}$ on average in workdays. Followed by Sands with 6485 visitors and COD with 4979 visitors. On holidays, the total number of visitors leaving Venetian, COD and Sands for the four depots rises up to 12,100, 6766 and 5999, respectively. 
Table 2 The statistical result of schedules for FSBs at each depot

\begin{tabular}{|c|c|c|c|c|c|}
\hline Casinos & Border Gate $(L)$ & Border Gate $(R)$ & Ferry Terminal & Pac On Pier & Total \\
\hline \multicolumn{6}{|c|}{ The arrival schedules of each depot (workday) } \\
\hline City of Dreams & 121 & 75 & 121 & 89 & 406 \\
\hline Venetian & 106 & 158 & 105 & 172 & 541 \\
\hline Plaza & 1 & 46 & 15 & 30 & 91 \\
\hline Sands Cotai Central & 88 & 65 & 55 & 94 & 302 \\
\hline Galaxy & 97 & 110 & 82 & 99 & 388 \\
\hline Grand Emperor & 57 & 103 & 74 & 10 & 244 \\
\hline Lisboa & 34 & 119 & 115 & 18 & 286 \\
\hline Grand Lisboa & 59 & 123 & 90 & 23 & 295 \\
\hline Wynn & 46 & 199 & 119 & 68 & 432 \\
\hline L'Arc & 36 & 1 & 44 & 1 & 80 \\
\hline Star World & 90 & 47 & 96 & 25 & 258 \\
\hline MGM & 28 & 93 & 82 & 19 & 222 \\
\hline Sands & 75 & 182 & 130 & 75 & 462 \\
\hline Babylon & 22 & 38 & 51 & 1 & 111 \\
\hline Golden Dragon & 1 & 65 & 32 & 1 & 97 \\
\hline Casa Real & 1 & 67 & 36 & 1 & 103 \\
\hline Oceanus & 1 & 89 & 1 & 1 & 89 \\
\hline Total & 859 & 1579 & 1247 & 722 & 4407 \\
\hline \multicolumn{6}{|c|}{ The departure schedules of each depot (workday) } \\
\hline City of Dreams & 120 & 72 & 120 & 88 & 400 \\
\hline Venetian & 100 & 155 & 106 & 165 & 526 \\
\hline Plaza & 1 & 40 & 15 & 28 & 83 \\
\hline Sands Cotai Central & 90 & 64 & 57 & 95 & 306 \\
\hline Galaxy & 95 & 112 & 88 & 97 & 392 \\
\hline Grand Emperor & 57 & 99 & 73 & 10 & 239 \\
\hline Lisboa & 35 & 120 & 115 & 12 & 282 \\
\hline Grand Lisboa & 60 & 121 & 89 & 14 & 284 \\
\hline Wynn & 50 & 181 & 116 & 60 & 407 \\
\hline L'Arc & 38 & 1 & 45 & 1 & 45 \\
\hline Star World & 88 & 46 & 95 & 25 & 254 \\
\hline MGM & 35 & 73 & 82 & 18 & 208 \\
\hline Sands & 74 & 172 & 127 & 75 & 448 \\
\hline Babylon & 24 & 39 & 51 & 1 & 114 \\
\hline Golden Dragon & 1 & 64 & 32 & 1 & 96 \\
\hline Casa Real & 1 & 65 & 35 & 1 & 100 \\
\hline Oceanus & 1 & 86 & 1 & 1 & 86 \\
\hline Total & 646 & 545 & 1246 & 118 & 4270 \\
\hline
\end{tabular}


Table 2 The statistical result of schedules for FSBs at each depot (continued)

\begin{tabular}{|c|c|c|c|c|c|}
\hline Casinos & Border Gate $(L)$ & Border Gate $(R)$ & Ferry Terminal & Pac On Pier & Total \\
\hline \multicolumn{6}{|c|}{ The arrival schedules of each depot (holiday) } \\
\hline City of Dreams & 135 & 104 & 123 & 90 & 452 \\
\hline Venetian & 114 & 165 & 106 & 174 & 559 \\
\hline Plaza & 1 & 55 & 17 & 31 & 103 \\
\hline Sands Cotai Central & 92 & 75 & 60 & 98 & 325 \\
\hline Galaxy & 98 & 120 & 90 & 96 & 404 \\
\hline Grand Emperor & 57 & 101 & 75 & 12 & 245 \\
\hline Lisboa & 35 & 118 & 114 & 19 & 286 \\
\hline Grand Lisboa & 69 & 138 & 93 & 25 & 325 \\
\hline Wynn & 48 & 196 & 123 & 69 & 436 \\
\hline L'Arc & 34 & 1 & 43 & 1 & 43 \\
\hline Star World & 95 & 49 & 99 & 24 & 267 \\
\hline MGM & 35 & 95 & 85 & 18 & 233 \\
\hline Sands & 78 & 185 & 139 & 79 & 481 \\
\hline Babylon & 21 & 37 & 48 & 1 & 106 \\
\hline Golden Dragon & 1 & 64 & 33 & 1 & 97 \\
\hline Casa Real & 1 & 66 & 34 & 1 & 100 \\
\hline Oceanus & 1 & 90 & 1 & 1 & 90 \\
\hline Total & 662 & 586 & 1282 & 121 & 4552 \\
\hline \multicolumn{6}{|c|}{ The departure schedules of each depot (holiday) } \\
\hline City of Dreams & 134 & 105 & 121 & 89 & 449 \\
\hline Venetian & 115 & 168 & 108 & 169 & 560 \\
\hline Plaza & 1 & 41 & 16 & 29 & 86 \\
\hline Sands Cotai Central & 93 & 65 & 59 & 97 & 314 \\
\hline Galaxy & 99 & 113 & 89 & 99 & 400 \\
\hline Grand Emperor & 58 & 99 & 74 & 11 & 242 \\
\hline Lisboa & 34 & 121 & 116 & 13 & 284 \\
\hline Grand Lisboa & 61 & 123 & 88 & 15 & 287 \\
\hline Wynn & 55 & 183 & 115 & 61 & 414 \\
\hline L'Arc & 39 & 1 & 44 & 1 & 44 \\
\hline Star World & 88 & 47 & 96 & 27 & 258 \\
\hline MGM & 34 & 74 & 83 & 17 & 208 \\
\hline Sands & 75 & 173 & 128 & 79 & 455 \\
\hline Babylon & 22 & 38 & 53 & 1 & 113 \\
\hline Golden Dragon & 1 & 63 & 35 & 1 & 98 \\
\hline Casa Real & 1 & 67 & 32 & 1 & 99 \\
\hline Oceanus & 1 & 88 & 1 & 1 & 88 \\
\hline Total & 658 & 550 & 1257 & 123 & 4399 \\
\hline
\end{tabular}


Table 3 The statistical of transported visitors of each depot

\begin{tabular}{|c|c|c|c|c|c|}
\hline Casinos & Border Gate $(L)$ & Border Gate $(R)$ & Ferry Terminal & Pac On Pier & Total \\
\hline \multicolumn{6}{|c|}{ The total number of arrivals at each depot (workday) } \\
\hline City of Dreams & 1536 & 985 & 1608 & 1266 & 5395 \\
\hline Venetian & 1367 & 2579 & 3457 & 5708 & 13,111 \\
\hline Plaza & 1 & 189 & 24 & 259 & 472 \\
\hline Sands Cotai Central & 679 & 545 & 479 & 657 & 2360 \\
\hline Galaxy & 788 & 986 & 658 & 988 & 3420 \\
\hline Grand Emperor & 187 & 1045 & 339 & 17 & 1588 \\
\hline Lisboa & 171 & 1499 & 739 & 19 & 2428 \\
\hline Grand Lisboa & 209 & 1532 & 1009 & 59 & 2809 \\
\hline Wynn & 328 & 1947 & 95 & 464 & 2834 \\
\hline L'Arc & 259 & 1 & 579 & 1 & 579 \\
\hline Star World & 608 & 602 & 790 & 25 & 2025 \\
\hline MGM & 201 & 1201 & 1550 & 19 & 2971 \\
\hline Sands & 489 & 2201 & 149 & 1389 & 4228 \\
\hline Babylon & 179 & 245 & 108 & 1 & 532 \\
\hline Golden Dragon & 1 & 608 & 87 & 1 & 695 \\
\hline Casa Real & 1 & 379 & 300 & 1 & 679 \\
\hline Oceanus & 1 & 745 & 1 & 1 & 745 \\
\hline Total & 4098 & 5981 & 11,971 & 1433 & 46,871 \\
\hline \multicolumn{6}{|c|}{ The total number of departures at each depot (workday) } \\
\hline City of Dreams & 1909 & 843 & 1049 & 1178 & 4979 \\
\hline Venetian & 2034 & 2708 & 2956 & 3803 & 11,501 \\
\hline Plaza & 1 & 79 & 120 & 145 & 344 \\
\hline Sands Cotai Central & 457 & 525 & 322 & 459 & 1763 \\
\hline Galaxy & 596 & 788 & 798 & 809 & 2991 \\
\hline Grand Emperor & 827 & 1259 & 693 & 67 & 2846 \\
\hline Lisboa & 627 & 1246 & 1179 & 219 & 3271 \\
\hline Grand Lisboa & 998 & 1298 & 984 & 159 & 3439 \\
\hline Wynn & 345 & 1409 & 901 & 455 & 3110 \\
\hline L'Arc & 149 & 1 & 203 & 1 & 203 \\
\hline Star World & 989 & 349 & 1002 & 147 & 2487 \\
\hline MGM & 235 & 946 & 845 & 126 & 2152 \\
\hline Sands & 1398 & 1980 & 1709 & 1398 & 6485 \\
\hline Babylon & 374 & 209 & 356 & 1 & 939 \\
\hline Golden Dragon & 1 & 879 & 89 & 1 & 968 \\
\hline Casa Real & 1 & 639 & 404 & 1 & 1043 \\
\hline Oceanus & 1 & 708 & 1 & 1 & 708 \\
\hline Total & 6995 & 5710 & 13,610 & 1671 & 49,229 \\
\hline
\end{tabular}


Table 3 The statistical of transported visitors of each depot (continued)

\begin{tabular}{|c|c|c|c|c|c|}
\hline Casinos & Border Gate $(L)$ & Border Gate $(R)$ & Ferry Terminal & Pac On Pier & Total \\
\hline \multicolumn{6}{|c|}{ The total number of arrivals at each depot (holiday) } \\
\hline City of Dreams & 1636 & 1009 & 1698 & 1269 & 5612 \\
\hline Venetian & 1517 & 2779 & 3557 & 5758 & 13,611 \\
\hline Plaza & 1 & 195 & 35 & 264 & 494 \\
\hline Sands Cotai Central & 699 & 565 & 499 & 647 & 2410 \\
\hline Galaxy & 858 & 1086 & 678 & 978 & 3600 \\
\hline Grand Emperor & 189 & 1055 & 355 & 32 & 1631 \\
\hline Lisboa & 179 & 1599 & 768 & 35 & 2581 \\
\hline Grand Lisboa & 307 & 1732 & 1019 & 79 & 3137 \\
\hline Wynn & 358 & 1957 & 93 & 424 & 2832 \\
\hline L'Arc & 269 & 1 & 552 & 1 & 552 \\
\hline Star World & 638 & 622 & 787 & 23 & 2070 \\
\hline MGM & 231 & 1209 & 1557 & 49 & 3046 \\
\hline Sands & 559 & 2205 & 145 & 1259 & 4168 \\
\hline Babylon & 169 & 225 & 101 & 1 & 495 \\
\hline Golden Dragon & 1 & 552 & 83 & 1 & 635 \\
\hline Casa Real & 1 & 329 & 346 & 1 & 675 \\
\hline Oceanus & 1 & 705 & 1 & 1 & 705 \\
\hline Total & 4456 & 5847 & 12,273 & 1331 & 48,254 \\
\hline \multicolumn{6}{|c|}{ The total number of departures at each depot (holiday) } \\
\hline City of Dreams & 2209 & 963 & 1449 & 1378 & 5999 \\
\hline Venetian & 2134 & 2903 & 3254 & 3809 & 12,100 \\
\hline Plaza & 1 & 59 & 101 & 87 & 247 \\
\hline Sands Cotai Central & 437 & 573 & 122 & 409 & 1541 \\
\hline Galaxy & 596 & 858 & 597 & 709 & 2760 \\
\hline Grand Emperor & 807 & 1059 & 499 & 65 & 2430 \\
\hline Lisboa & 607 & 1036 & 1074 & 212 & 2929 \\
\hline Grand Lisboa & 1236 & 1598 & 1084 & 150 & 4068 \\
\hline Wynn & 375 & 1309 & 905 & 475 & 3064 \\
\hline L'Arc & 129 & 1 & 202 & 1 & 202 \\
\hline Star World & 949 & 359 & 1005 & 157 & 2470 \\
\hline MGM & 205 & 926 & 843 & 106 & 2080 \\
\hline Sands & 1598 & 2081 & 1809 & 1278 & 6766 \\
\hline Babylon & 304 & 239 & 323 & 1 & 866 \\
\hline Golden Dragon & 1 & 829 & 80 & 1 & 909 \\
\hline Casa Real & 1 & 489 & 443 & 1 & 932 \\
\hline Oceanus & 1 & 658 & 1 & 1 & 658 \\
\hline Total & 7243 & 5581 & 13,790 & 1541 & 50,021 \\
\hline
\end{tabular}


According to the data of arrival at depots, during workdays, the total number of arrivals at Border Gate (L) is 7001 and 584 arrivals during an hour on average. The total number of arrivals at Border Gate (R) is 17,288 and 1440 arrivals during an hour on average. The total numbers of arrivals at Ferry Terminal are 11,971 and 997 during an hour on average. While there are total 10,870 arrivals at Taipa Pac On Pier and 905 during an hour on average. Hence, it is concluded that Border Gate (R) is the depot that has the most arrivals, while Pac On Pier is the least. During holidays, the total arrivals at Border Gate (L) are 7609 and average 634 an hour with an increase of $8.5 \%$. The total arrivals at Border Gate (R) are 17,824 and average 1485 during an hour on average with an increase of $3.1 \%$. The total arrivals at Ferry Terminal are 12,273 and average 1022 during an hour with an increase of $2.5 \%$. And the total arrivals at Pac On Pier are 10,817 and average 901 during an hour with a decline of $0.05 \%$. Therefore, we conclude that Border Gate (R) is the depot that has the most arrivals, while Pac On Pier is the least. Table 3 is the statistics of transported visitors at each depot.

\subsection{Discussion and analysis}

\subsubsection{Discussion}

The time period is set uniformly from 9:00 AM to 9:00 PM. In this paper, since this period can fit with the FSB scheduling timetable from the above 17 casinos and include both peak and valley hours. To ensure the validity of the research, we select the largest number of visitors during the peak hours of holiday as the normal passenger flow at the four depots and casinos. For the sake of convenience, we set $2 \mathrm{~h}$ as a time period. Table 4 shows the largest passenger number during the peak hours of holiday at each of the casinos and the depots and Table 5 lists the maximum transit time of FSBs between the depots and the casinos.

Furthermore, a tolerance upper limit of the waiting time is needed to maintain the current passenger service level. Shi et al. (2010) investigated the possible maximum waiting time by collecting the questionnaires distributed at each depot and obtained a 16.3 -min period as the tolerance upper limit of the waiting time. That means the time interval between any two FSBs cannot exceed $16.3 \mathrm{~min}$. Otherwise, the service level will decrease. In addition, although the capacity of the FSBs at different casinos is different, the most FSBs have the capacity with the average of 47 seats. Hence, we unify the capacity of FSB as 47 seats for the convenience of computation.

As to the report from Macau Transport Bureau in 2013, the number of full-time drivers in these 17 casinos is 608 . To keep the current maximum service level, especially for the demands on holidays, each casino tends to employ many FSB drivers. However, from the perspective of FSB's operation cost, it is necessary to optimise the number of drivers to reduce their operating costs. FSB drivers are classified into full-time and part-time employees in this paper. We aim to reduce the quantity of full-time drivers in casinos, use part-time drivers to meet the demands of passengers on holidays. However, it is impossible to employ the part-time drivers as many as possible because the restriction of labour law of Macau, so we set part-time driver's hours cannot exceed 50\% of the day's minimum requirement in this paper. 


\subsubsection{Analysis}

The first part is to optimise the population of FSB. The model includes a series of LPs with each casino and each depot at six different 2-h time intervals. For the sake of clarity, we take the case of COD as one example to show how to optimise its FSB population. The basic procedure is as follows: First, we run the LP based on the data of the largest passenger number and the maximum transit time between COD and the four depots at the six different 2-h time intervals; Second, we select the maximum number of FSBs COD should provide to match the passenger demand all the day at each depot. Table 6 shows the optimal population of the FSBs for each casino. For instance, we should arrange six, three, four and three FSBs back and forth for the routes between COD and the four depots, respectively. Finally, the optimal number of FSBs is obtained with a value of 388 . The report from Macau Transport Bureau in 2013 indicates that the present population of the FSBs among the 17 casinos is 689 . Thus, the result can reduce the population of the FSBs by $43.68 \%$. Therefore, the optimised effect of the model is significant. Obviously, the optimisation will lower both the operating costs of the casinos and traffic pressure of Macau greatly.

Table 4 The largest passenger number at each casino and each depot

\begin{tabular}{|c|c|c|c|c|c|c|c|c|}
\hline \multirow[b]{2}{*}{ Casinos } & \multicolumn{2}{|c|}{ Border Gate $(L)$} & \multicolumn{2}{|c|}{ Border Gate $(R)$} & \multicolumn{2}{|c|}{ Ferry Terminal } & \multicolumn{2}{|c|}{ Pac On Pier } \\
\hline & Dep. & Arr. & Dep. & Arr. & Dep. & Arr. & Dep. & Arr. \\
\hline City of Dreams & 580 & 522 & 498 & 105 & 703 & 889 & 257 & 447 \\
\hline Venetian & 479 & 489 & 589 & 608 & 1289 & 1364 & 956 & 1699 \\
\hline Plaza & 1 & 1 & 35 & 39 & 45 & 40 & 30 & 35 \\
\hline Sands Cotai Central & 389 & 402 & 399 & 245 & 108 & 355 & 401 & 609 \\
\hline Galaxy & 502 & 655 & 609 & 767 & 408 & 455 & 689 & 709 \\
\hline Grand Emperor & 238 & 154 & 175 & 253 & 154 & 479 & 50 & 35 \\
\hline Lisboa & 228 & 179 & 389 & 356 & 249 & 955 & 59 & 36 \\
\hline Grand Lisboa & 404 & 207 & 678 & 306 & 431 & 705 & 54 & 58 \\
\hline Wynn & 306 & 48 & 307 & 286 & 455 & 299 & 155 & 276 \\
\hline L'Arc & 187 & 56 & 1 & 1 & 77 & 89 & 1 & 1 \\
\hline Star World & 395 & 177 & 147 & 99 & 245 & 299 & 46 & 80 \\
\hline MGM & 156 & 178 & 409 & 89 & 287 & 478 & 67 & 98 \\
\hline Sands & 490 & 123 & 689 & 356 & 432 & 586 & 321 & 378 \\
\hline Babylon & 231 & 89 & 176 & 34 & 59 & 132 & 1 & 1 \\
\hline Golden Dragon & 1 & 1 & 231 & 244 & 34 & 79 & 1 & 1 \\
\hline Casa Real & 1 & 1 & 178 & 145 & 56 & 65 & 1 & 1 \\
\hline Oceanus & 1 & 1 & 19 & 12 & 1 & 1 & 1 & 1 \\
\hline
\end{tabular}

Dep. and Arr. are short for Departure and Arrival, respectively.

The second part is to optimise the population of FSB's drivers and the basic procedure is as follows: First, we run the LP based on the data of the largest passenger number and the maximum transit time and the data from the previous optimising result at the six different 2-h time intervals. Second, we select the maximum number of FSBs to match the 
passenger demand all the day at each depot (Table 7 shows the optimal population of the FSB's driver for casinos). Finally, the optimal number of FSB's full-time drivers is obtained with the number of 404 and that of the number of the part-time drivers is 186. The report from Macau Transport Bureau in 2013 shows the present population of the FSB's full-time driver among the 17 casinos is 608 . Thus, the result can reduce the population of the FSB's drivers by $33.6 \%$. Therefore, the optimised effect of the model is significantly obvious. Furthermore, this optimisation will lower the operating costs of the casinos greatly.

Table 5 The maximum transit time of FSB back and forth between depots and casinos

\begin{tabular}{|c|c|c|c|c|c|c|c|c|}
\hline \multirow[b]{2}{*}{ Casinos } & \multicolumn{2}{|c|}{ Border Gate $(L)$} & \multicolumn{2}{|c|}{ Border Gate $(R)$} & \multicolumn{2}{|c|}{ Ferry Terminal } & \multicolumn{2}{|c|}{ Pac On Pier } \\
\hline & Dep. & Arr. & Dep. & Arr. & Dep. & Arr. & Dep. & Arr. \\
\hline City of Dreams & 48 & 24 & 21 & 26 & 22 & 20 & 26 & 19 \\
\hline Venetian & 46 & 29 & 22 & 25 & 28 & 16 & 28 & 17 \\
\hline Plaza & 1 & 1 & 26 & 27 & 30 & 19 & 30 & 20 \\
\hline Sands Cotai Central & 50 & 26 & 23 & 25 & 24 & 21 & 28 & 20 \\
\hline Galaxy & 48 & 30 & 24 & 25 & 29 & 19 & 28 & 18 \\
\hline Grand Emperor & 22 & 20 & 21 & 25 & 19 & 16 & 31 & 27 \\
\hline Lisboa & 21 & 24 & 20 & 24 & 12 & 16 & 30 & 27 \\
\hline Grand Lisboa & 20 & 25 & 22 & 24 & 14 & 18 & 32 & 25 \\
\hline Wynn & 53 & 21 & 25 & 28 & 17 & 15 & 28 & 20 \\
\hline L'Arc & 51 & 20 & 1 & 1 & 16 & 12 & 1 & 1 \\
\hline Star World & 53 & 21 & 28 & 30 & 17 & 29 & 16 & 20 \\
\hline MGM & 52 & 22 & 26 & 29 & 15 & 12 & 28 & 18 \\
\hline Sands & 11 & 12 & 11 & 16 & 8 & 11 & 19 & 20 \\
\hline Babylon & 11 & 13 & 13 & 17 & 8 & 13 & 1 & $\backslash$ \\
\hline Golden Dragon & $\backslash$ & 1 & 17 & 18 & 10 & 18 & 1 & 1 \\
\hline Casa Real & 1 & 1 & 16 & 18 & 13 & 19 & 1 & 1 \\
\hline Oceanus & 1 & 1 & 18 & 19 & 1 & 1 & 1 & 1 \\
\hline
\end{tabular}

Dep. and Arr. are short for Departure and Arrival, respectively.

The last part is to optimise the operational cost of casinos. From the above results, we could reduce $301 \mathrm{FSBs}$ and 204 drivers of FSB. In this paper, we select YUTONG $\mathrm{ZK} 6128 \mathrm{H} \mathrm{M} / \mathrm{T}$ (2009) as the standardised style of FSB in capacity for calculation. In present market, the retail price of YUTONG ZK6128H M/T is 900,000 HKD. Hence, the casinos could reduce $301 \times 900,000=270,900,000$ HKD in purchase of FSB. On the other hand, according to the present salary level of FSB's driver in Macau, each driver earns $15,800 \mathrm{HKD} /$ month. Therefore, the casinos could reduce $204 \times 189,600 \mathrm{HKD} /$ year $=38,678,400 \mathrm{HKD} /$ year in personnel cost for FSB's driver. It is apparent that the reduction effect in operational cost is significantly obvious. 
Table 6 The optimal population of FSB

\begin{tabular}{|c|c|c|c|c|c|c|c|c|c|}
\hline \multirow{2}{*}{ Casinos } & \multicolumn{2}{|c|}{ Border Gate $(L)$} & \multicolumn{2}{|c|}{ Border Gate $(R)$} & \multicolumn{2}{|c|}{ Ferry Terminal } & \multicolumn{2}{|c|}{ Pac On Pier } & \multirow[b]{2}{*}{ Total } \\
\hline & Dep. & Arr. & Dep. & Arr. & Dep. & Arr. & Dep. & Arr. & \\
\hline City of Dreams & 6 & 6 & 3 & 3 & 4 & 4 & 3 & 3 & 32 \\
\hline Venetian & 5 & 5 & 6 & 6 & 3 & 3 & 3 & 3 & 34 \\
\hline Plaza & 1 & 1 & 4 & 4 & 4 & 4 & 4 & 4 & 24 \\
\hline Sands Cotai Central & 4 & 4 & 3 & 3 & 3 & 3 & 3 & 3 & 26 \\
\hline Galaxy & 5 & 5 & 5 & 5 & 3 & 3 & 3 & 3 & 32 \\
\hline Grand Emperor & 5 & 5 & 3 & 3 & 2 & 2 & 4 & 4 & 28 \\
\hline Lisboa & 5 & 5 & 4 & 4 & 2 & 2 & 4 & 4 & 30 \\
\hline Grand Lisboa & 5 & 5 & 3 & 3 & 2 & 2 & 4 & 4 & 28 \\
\hline Wynn & 5 & 5 & 3 & 3 & 2 & 2 & 3 & 3 & 26 \\
\hline L'Arc & 6 & 6 & 1 & 1 & 2 & 2 & 1 & 1 & 4 \\
\hline Star World & 5 & 5 & 3 & 3 & 2 & 2 & 3 & 3 & 26 \\
\hline MGM & 5 & 5 & 3 & 3 & 2 & 2 & 3 & 3 & 26 \\
\hline Sands & 4 & 4 & 2 & 2 & 2 & 2 & 3 & 3 & 22 \\
\hline Babylon & 5 & 5 & 2 & 2 & 1 & 1 & 1 & 1 & 16 \\
\hline Golden Dragon & 1 & 1 & 2 & 2 & 2 & 2 & 1 & 1 & 8 \\
\hline Casa Real & 1 & 1 & 3 & 3 & 2 & 2 & 1 & 1 & 10 \\
\hline Oceanus & 1 & 1 & 2 & 2 & 1 & 1 & 1 & 1 & 4 \\
\hline Total & 65 & 65 & 51 & 51 & 38 & 38 & 40 & 40 & 376 \\
\hline
\end{tabular}

Dep. and Arr. are short for Departure and Arrival, respectively.

Table 7 The optimal population of FSB's drivers

\begin{tabular}{|c|c|c|c|c|c|c|c|c|c|c|c|}
\hline Drivers & $F$ & $P_{1}$ & $P_{2}$ & $P_{3}$ & $P_{4}$ & $P_{5}$ & $P_{6}$ & $P_{7}$ & \multirow{2}{*}{\multicolumn{3}{|c|}{ Total }} \\
\hline Time & $9-21$ & 9 & 10 & 11 & 12 & 13 & 14 & 15 & & & \\
\hline Number of drivers & 404 & 0 & 0 & 0 & 186 & 0 & 0 & 0 & & 590 & \\
\hline \multicolumn{12}{|l|}{ Constraints } \\
\hline 9:00-11:00 Needs & 1 & 1 & 1 & & & & & & 404 & $\geq$ & 336 \\
\hline 11:00-13:00 Needs & 0.5 & 1 & 1 & 1 & 1 & & & & 388 & $\geq$ & 287 \\
\hline 13:00-15:00 Needs & 0.5 & 1 & 1 & 1 & 1 & 1 & 1 & & 388 & $\geq$ & 388 \\
\hline 15:00-17:00 Needs & 1 & & 1 & 1 & 1 & 1 & 1 & 1 & 590 & $\geq$ & 451 \\
\hline 17:00-19:00 Needs & 1 & & & & 1 & 1 & 1 & 1 & 590 & $\geq$ & 552 \\
\hline 19:00-21:00 Needs & 1 & & & & & & 1 & 1 & 404 & $\geq$ & 220 \\
\hline Max full time & 1 & & & & & & & & 404 & $\leq$ & 608 \\
\hline Part-time limit & & 6 & 6 & 6 & 6 & 6 & 6 & 6 & 1116 & $\leq$ & 1117 \\
\hline
\end{tabular}




\section{Conclusions and suggestions}

\subsection{Conclusions}

In summary, this paper introduces the current status and difficulties about FSB, and selects 17 casinos and four depots for data collection, and proposes several mathematical models to optimise the population of FSB, the number of drivers for the purpose of reducing operational cost of casinos. After the first step of simulation, the results show that only 388 FSB needed for 17 casinos, which reduces FSBs from 689 to 388 with a reduction of $43.68 \%$. Then, after the second step of simulation, the results show that the current number of FSB driver is reduced from 608 to 404 with a reduction of $33.6 \%$. Finally, based on the optimal results of the population of FSB and the number of FSB's drivers, and we obtained a decrease of 270,900,000 HKD in purchase of FSB and $38,678,400 \mathrm{HKD} /$ year in personnel cost of FSB's drivers, which makes great contribution to the reduction of casino operational cost in Macau.

\subsection{Suggestions}

This paper provides the local government with some scientific and practical suggestions to reduce the traffic problems and the operational cost for casinos and improves the public transport situation in Macau. In addition, the paper provides a set of real data for academia to apply different frameworks to solve vehicle routing problems in further studies. The optimal result of this paper depends on the tolerance upper limit of the waiting time of passengers, to a large extent. Thus, we have to consider the impact of the waiting time on the optimal result through the sensitivity analysis. We take Venetian as one example in the follows: If the tolerance upper limit of the waiting time of passengers is reduced to $12.3 \mathrm{~min}$, the number of the FSBs from Venetian to Border Gate (L) will be increased to seven. Similarly, the number of FSB from Border Gate (L) to Venetian will be increased to seven. The number of FSBs in the remaining routes can be analysed similarly. Hence, if the tolerance upper limit of the waiting time is $12.3 \mathrm{~min}$, the optimal number of the FSBs will be 476. This means that the population of the FSBs in the 17 casinos will be increased by 22 vehicles if $1 \mathrm{~min}$ of the tolerance upper limit of the waiting time is reduced.

\section{Acknowledgements}

The authors are thankful for support from The Science and Technology Development Fund of Macau (Grant No. 069/2011/A).

\section{References}

AMCM (2012) Economic Statistics from Monetary Authority of Macao, Retrieved 23 December, 2012, http://www.amcm.gov.mo

Bahad, Y.M. and Balachandran, B.V. (1993) 'Cost driver optimization in activity-based costing', The Accounting Review, Vol. 68, pp.563-575. 
Chotiros, S., Gerhard, R. and Bock, H.G. (2008) 'Solving city bus scheduling problems in Bangkok by Eligen-algorithm', Modeling, Simulation and Optimization of Complex Processes, Vol. 1, pp.557-564.

Cooper, R. (1989) 'The rise of activity-based costing part three: How many cost drivers do you need, and how do you select them?', Journal of Cost Management, Vol. 2, pp.34-46.

Dantzig, G. and Ramser, J. (1959) 'The truck dispatching problem', Management Science, Vol. 6, pp.89-91.

DSEC (2012) DSEC - For the Current Data of Visitor Arrivals by Place of Residence, Retrieved 8 January, 2012, http://www.dsec.gov.mo

Gronalt, M., Richard, F.H. and Reimann, M. (2003) 'New savings based algorithms for timeconstrained pickup and delivery of full truckloads', European Journal of Operational Research, Vol. 151, pp.520-535.

Hadjar, A. and Soumis, F. (2009) 'Dynamic windows reduction for the multiple depot vehicle scheduling problem with time windows', Computers \& Operations Research, Vol. 36, pp.2160-2172.

Kim, K.J. and Han, I. (2003) 'Application of a hybrid genetic algorithm and neural network approach in activity-based costing', Expert Systems with Applications, Vol. 24, pp.73-77.

Levitan, A. and Gupta, A.M. (1996) 'Using genetic algorithms to optimize the selection of cost drivers in activity-based costing', Intelligent Systems in Accounting, Finance and Management, Vol. 5, pp.129-145.

Macau Hub (2013) Macau Expected to Receive between 34 and 35 Million Tourists in 2013, Retrieved 15 March, 2013, http://www.macauhub.com.mo

Qi, L. (2009) 'Vehicle scheduling with combinable delivery and pickup operations', Operations Research Letters, Vol. 37, pp.399-404.

Savelsberg, M. and Sol, M. (1998) 'Dynamic routing of independent vehicles', Operations Research, Vol. 46, pp.474-490.

Shi, Y.D., Tang, H.J., Zhang, H.C., Hu, X.Y. and Sun, B. (2010) 'Study on the optimal operation of free shuttle buses in Macau', Journal of Macau University of Science and Technology, Vol. 4, pp.31-46.

Stefan, I., Desaulniers, G., Desrosiers, J. and Hadjar, A. (2010) 'Path-reduced costs for eliminating arcs in routing and scheduling', Informs Journal on Computing, Vol. 22, pp.297-313.

Steinzen, I., Kliewer, N., Vitali, G. and Leena, S. (2010) 'A time-space network approach for the integrated vehicle and crew-scheduling problem with multiple depots', Transportation Science, Vol. 44, pp.367-382.

Yang, Z.Z., Yu, B. and Cheng, C. (2007) 'A parallel ant colony algorithm for bus network optimization model tests', Computer-Aided Civil and Infrastructure Engineering, Vol. 22, pp.44-55. 